\title{
DIFICULDADES DE APRENDIZAGEM NA LEITURA E NA ESCRITA DE
} ALUNOS DO $2^{\circ}$ ANO DO ENSINO FUNDAMENTAL I

\author{
https://dx.doi.org/10.48097/2674-8673.2021n5p05
}

\author{
Andreza Marques de Melo Lima ${ }^{1}$ \\ Cláudia Patrícia Pinheiro Viana Ximenes ${ }^{2}$ \\ Silvia Rodrigues Cavalcanti Isaltino ${ }^{3}$
}

\section{RESUMO}

O presente trabalho teve por objetivo analisar a intervenção pedagógica dos professores frente às dificuldades de aprendizagem na leitura e na escrita de alunos do $2^{\circ}$ ano do ensino fundamental I. Optou-se por uma pesquisa de caráter qualitativa, bibliográfica e com pesquisa de campo, através do uso de questionário online, devido ao momento da pandemia da COVID- 19. Participaram quatro (4) professores da escola particular Felipe Magalhães, situada em Jaboatão dos Guararapes - PE. O embasamento teórico contou com a contribuição de Soares (1998), Veiga (2002), Leite (2012), dentre outros. Por fim, verific ouse que as dificuldades de aprendizagem advêm de diversos fatores que podem atingir grande parte dos alunos, representando um desafio que precisa ser superado no âmbito escolar. A intervenção pedagógica para a superação de tais dificuldades deve ser no sentido de mudança no papel do professor e da metodologia adotada em sala de aula, criando projetos, momentos lúdicos e oficinas pedagógicas com o intuito de prevenir e/ou acabar com as dificuldades identificadas.

Palavras-chave: Dificuldade de aprendizagem. Papel do professor. Intervenção pedagógica.

Data de submissão: $12 / 03 / 2021$

Data de aprovação: 14/05/2021

\begin{abstract}
The present study aimed to analyze the pedagogical intervention of teachers in the face of learning difficulties in reading and writing in students of the 2nd year of elementary school I. We opted for a qualitative, bibliographic research with field research, through the use of an

\footnotetext{
${ }^{1}$ Graduanda do Curso de Licenciatura em Pedagogia da Faculdade Metropolitana da Grande Recife.

E-mail: andrezamelox@gmail.com

${ }^{2}$ Graduanda do Curso de Licenciatura em Pedagogia da Faculdade Metropolitana da Grande Recife.

E-mail: cpatriciavianaximenes@outlook.com

${ }^{3}$ Professora/Orientadora do Curso de Licenciatura em Pedagogia da Faculdade Metropolitana da Grande Recife.

E-mail: silvinharca@hotmail.com
} 
online questionnaire, due to the time of the COVID-19 pandemic. Four (4) teachers from the private school Felipe Magalhães, located in Jaboatão dos Guararapes - PE, participated. The theoretical basis had the contribution of Soares (1998), Veiga (2002), Leite (2012), among others. Finally, it was found that learning difficulties arise from several factors that can affect a large part of students, representing a challenge that needs to be overcome in the school environment. The pedagogical intervention to overcome such difficulties must be in the sense of changing the role of the teacher and the methodology adopted in the classroom, creating projects, playful moments and pedagogical workshops in order to prevent and / or end the difficulties identified.

Keywords: Learning disability. Teacher's role. Pedagogical intervention.

\section{INTRODUÇÃO}

Ao refletir sobre a educação escolar é possível perceber que existem inúmeros elementos que influenciam no processo de ensino-aprendizagem dentro do contexto de sala de aula. Dentre esses, é necessário considerar as dificuldades de aprendizagem, que aparecem como obstáculos na condução desse processo. Entretanto, é importante ter em mente que tais dificuldades não impedem a aquisição da aprendizagem, visto que todo aluno é capaz de aprender, desde que a ele seja dado todo suporte necessário para sua construção do conhecimento.

Em estudo realizado anteriormente por uma das presentes pesquisadoras, foi possível analisar a maneira como as dificuldades de aprendizagem podem ser abordadas através da intervenção psicopedagógica, gerando assim uma alternativa para amenizar o problema em questão.

Contudo, considerando a necessidade de se observar o referido tema, através de uma perspectiva multidisciplinar, e reconhecendo o fundamental papel do professor na condução desse processo educativo, o referido trabalho volta-se para discutir as dificuldades de aprendizagem, através de um olhar pedagógico, centrado na sala de aula do ensino fundamental I.

De acordo com Leite (2012), as dificuldades de aprendizagem (DA) correspondem a uma categoria ampla de fenômenos que podem influenciar negativamente no aprendizado, como por exemplo: a realidade socioeconômica da população, a falta de estímulo por parte da família, a formação inadequada dos professores, uma metodologia que não contempla as diversas formas de aprender dos estudantes, etc.

De tal modo, cabe ao professor em sala de aula, como mediador, ter um olhar crítico, ter a capacidade de avaliar e identificar qual o melhor método a ser usado para ajudar aquele aluno a superar essa dificuldade para não se tornar um trauma/bloqueio, causando desânimo, 
desinteresse ou até mesmo o abandono da escola. Cada pessoa tem uma forma própria de assimilar conhecimentos e traz consigo uma bagagem cultural. Então, diante das dificuldades encontradas, o papel do professor é o de ajudar a integrar o aluno no processo de aprendizagem. O professor precisa entender o aluno e entender o fato de que ele precisa aprender sobre o mundo de maneira cautelosa e no seu próprio tempo. (GADOTTI, 2003).

Nesse sentido, destaca-se o papel do professor na condução do processo de aprendizagem diante do aluno com dificuldade, gerenciando a construção do conhecimento, negociando com os seus desafios e as suas possibilidades, reconhecendo as diferenças dos seus alunos e considerando os conhecimentos e as experiências de vida que esses trazem consigo.

Assim, surge a motivação para desenvolver o presente trabalho, combinada com a experiência profissional das pesquisadoras, que atuam no $2^{\circ}$ ano do ensino fundamental e identificam alunos com tais dificuldades, principalmente na leitura e na escrita. Através dessa experiência foi possível perceber a necessidade de uma alta demanda de conhecimentos por parte dos professores para lidarem com as dificuldades na sala de aula, desenvolvendo práticas que não venham a excluir esse educando e nem o identificar como incapaz de aprender.

A partir disso algumas indagações surgiram. Quais são essas dificuldades de aprendizagem? Qual o papel do professor diante da dificuldade da criança na aprendizagem da leitura e da escrita? Qual proposta de intervenção pedagógica auxiliará alunos com dificuldades de aprendizagem na leitura e na escrita?

Levando em consideração a relevância do tema, a presente pesquisa pretende contribuir com as discussões voltadas para o cenário educacional, para a prática do professor dentro de sala de aula, e para as dificuldades de aprendizagem que surgem no processo escolar, desmistificando antigos conceitos que consideram tais alunos como incapazes de obter sucesso escolar.

\section{O PROCESSO DE APRENDIZAGEM DA LEITURA E DA ESCRITA}

Diferente do que se pensa no senso comum, o processo de aprendizagem da leitura e da escrita não se inicia no espaço escolar. Na verdade, esse processo acontece desde o início da vida da criança, através de diversas interações no seio familiar. Esse contato se estabelece através de atividades corriqueiras e cotidianas, estimulando, assim, a aquisição desses conhecimentos.

É preciso ter uma visão mais abrangente do processo de aprendizagem, uma vez que o 
indivíduo é um ser bastante complexo e há vários fatores que influenciam no seu desenvolvimento cognitivo, tais como: fatores genéticos e biológicos, o convívio social, os estímulos recebidos pela família, pela cultura local, pela escola, pelos amigos, pelos professores, etc. A aprendizagem requer a compreensão do indivíduo como um ser completo, levando em consideração os aspectos psicomotor, afetivo e cognitivo.

Assim, a educação recebida na escola, na família e na sociedade cumpre um papel primordial na constituição dos sujeitos, visto que tais instâncias interferem no desenvolvimento individual e, consequentemente, no desempenho da criança na aprendizagem. (VYGOTSKY, 1984).

Conforme se sabe, a leitura e a escrita são, desde sempre, muito importantes para a vida em sociedade, influenciando nas formas de comunicação e expressão e facilitando o diálogo entre os indivíduos. A escrita surgiu por volta de 3.000 a. C. O homem, mesmo sem a escrita, buscava comunicar-se através de desenhos realizados nas paredes das cavernas. Através desses desenhos revelou-se uma forma de comunicação humana, a qual servia para trocar mensagens, transmitir ideias, desejos, alegrias, sofrimentos e necessidades. Isso foi evoluindo ao longo dos anos, passando por símbolos até chegar às letras do nosso alfabeto.

Porém, junto com a evolução e a formação das civilizações em sociedade, vieram também práticas excludentes, as quais limitavam o ensino e aprendizagem da leitura e da escrita apenas para pessoas de classes sociais mais altas. Tal exclusão acarretou inúmeros problemas para grande parcela da sociedade, influenciando nos índices de dificuldade de aprendizagem.

No atual contexto escolar brasileiro, percebe-se que o país passou por um processo de democratização no acesso às escolas, garantindo que crianças de todas as classes sociais possam frequentar e construir conhecimentos nesse espaço educativo. Entretanto, tal acesso não veio combinado com a garantia da qualidade desse ensino, o qual ainda precisa ser melhorado. O processo de alfabetização não pode ser entendido como meramente o ensino para a "codificação" e a "decodificação". Alfabetizar vai além do simples ato de ler e escrever, conduzindo a outras práticas sociais. (CEEL 2007).

Tendo em vista que aprender deve ser um ato desejante do indivíduo que aprende, vale destacar que a escola precisa suscitar no aluno o desejo de aprender, conduzindo a aprendizagem não através de métodos tradicionais, mecânicos e esvaziados de sentido, mas sim de forma significativa, com descontração e oferecendo situações interessantes e estimulantes, pois quando o ato de aprender é colocado como algo prazeroso e satisfatório tem-se o desejo e a vontade de aprender. 
Segundo Kleiman (2002), a aprendizagem da criança na escola deve estar fundamentada na leitura, pois interpretar e compreender os elementos sociais são aspectos fundamentais e sem essas bases não tem como a criança obter sucesso em nenhuma atividade que lhe for apresentada.

\section{Dificuldade de aprendizagem na leitura e escrita}

Nas últimas décadas um dos problemas educacionais que mais vem ganhando destaque nos debates acadêmicos são as dificuldades de aprendizagem. Para melhor compreender tal discussão, é preciso levar em consideração que o problema de aprendizagem não deve ser combatido apenas a partir do momento que a criança já está apresentando tais dificuldades na escola, visto que a prevenção e o prévio diagnóstico são fundamentais para evitar que essas se instalem.

Apesar de ser um fenômeno antigo, não é fácil apresentar uma definição para as dificuldades de aprendizagem de leitura e escrita, pois essas englobam diferentes fatores como: desenvolvimento social, aspectos comportamentais, fatores cognitivos, etc. Kikr (1962) ressalta que uma dificuldade de aprendizagem se refere a um transtorno ou desenvolvimento lento em um ou mais processo da fala, linguagem, leitura, escrita ou outras áreas escolares, resultante de uma deficiência causada por uma possível disfunção cerebral, alteração emocional ou condutual. As dificuldades de aprendizagem da leitura podem revelar-se na dificuldade da leitura oral, dificuldade na leitura silenciosa e dificuldade na compreensão da leitura e consequentemente da escrita.

Segundo Nunes (2001), "todas as crianças têm dificuldades na leitura e na escrita, que é uma atividade complexa. Até certo ponto, o ritmo que ela supera essas dificuldades pode ser antecipado". Nota-se, assim, que as dificuldades de aprendizagem estão presentes no cotidiano das escolas e afetam todos os tipos de educandos.

Conforme a visão de Pain (1992):

O problema de aprendizagem é considerado um processo diferente do contrário de aprender. É um processo particular de um sistema que se equilibra e precisa adotar determinado tipo de comportamento que determina o não aprender e que cumpre assim sua função positiva. (PAIN, 1992, p. 10).

No entanto, vale ressaltar que cada vez mais é possível encontrar alunos desmotivados a aprender no contexto escolar. Por um lado, pode-se atribuir determinada dificuldade de aprendizagem ao desinteresse do aluno, mas por outro ângulo, a falta de interesse e dificuldade do aluno muitas vezes acontece porque esse não vê sentido naquilo que está sendo 
ensinado em sala de aula. A falta de uma metodologia e de um conteúdo adequado, que converse com a realidade daquele estudante e que possibilite uma participação ativa, influencia na condução do processo de ensino-aprendizagem e, logo, nos índices de dificuldades de aprendizagem da leitura e da escrita.

Diante disso, verifica-se a necessidade de uma formação profissional no sentido de promover uma gama de conhecimentos para que os professores saibam lidar com essas situações em sala de aula, para assim evitar o desinteresse, a evasão, o fracasso escolar, a rotulação e/ou exclusão desses alunos do contexto escolar.

Além disso, a linguagem oral também precisa ser bem trabalhada, porque a criança costuma escrever da forma como se fala/escuta. Simões (2006) ressalta que o professor dos anos iniciais deve conhecer os aspectos fônicos da língua portuguesa para ajudar a criança em relação à língua falada e escrita. Isso exige do professor competência específica para minimizar as dificuldades.

Por fim, é interessante que a intervenção frente às dificuldades de aprendizagem da leitura e escrita no contexto da sala de aula aconteça através de elementos lúdicos, que possam possibilitar uma experiência prazerosa para os alunos, pois assim esses poderão construir os conhecimentos necessários através de uma aprendizagem mais significativa.

\section{O papel do professor na condução do processo educativo escolar frente à dificuldade de aprendizagem}

Se o professor é fundamental na condução do processo educativo escolar como um todo, a sua importância fica ainda mais evidente diante da dificuldade de aprendizagem. $\mathrm{O}$ professor, enquanto mediador da construção do conhecimento, estabelece um contato direto e cotidiano com os seus alunos, sendo possível assim conhecê-los, identificar determinada dificuldade e buscar meios para contornar tal situação.

Cada criança precisa ser compreendida em suas necessidades particulares e cabe ao professor, com seu conhecimento e experiência, saber usar a sua trajetória pedagógica como docente para amenizar e ajudar nesse processo. Para Coelho e José (1996, p. 12-13) “o professor deve estar sempre atento às etapas do desenvolvimento do aluno, colocando-se na posição de facilitador da aprendizagem e calcando seu trabalho no respeito mútuo, na confiança e afeto".

De tal maneira, destaca-se o papel do professor frente às dificuldades de aprendizagem, uma vez que através dele é possível conhecer melhor o porquê das dificuldades dos alunos, sabendo como intervir diante de cada situação. Cabe ao professor eleger o melhor método para 
ensinar aquele aluno, diversificando a metodologia em sala de aula, adaptando os instrumentos de forma a respeitar a forma de cada um de aprender, do seu jeito, no seu tempo e ritmo próprio.

Bossa (1994) assinala que o grande salto para um trabalho efetivo, eficiente e eficaz é o professor descentrar, ou seja, sair de si mesmo para atender e agir com a lógica do outro e, a partir disso, reconstruir a história do sujeito, respeitando a sua singularidade. É perceber em que movimento este ser está indiferenciado, separado ou integrado frente ao conhecimento para o início do resgate.

O professor deve refletir sobre a prática que está sendo utilizada em sala no processo de ensino-aprendizagem, planejando, elaborando e mediando suas aulas a partir da compreensão da particularidade de cada aluno, procurando sempre motivá-lo a aprender. Uma boa mediação estimula a criatividade através de práticas lúdicas e dinâmicas que ajudam o aluno a produzir, criar e construir, fazendo-o pensar ativamente. Nessa perspectiva, construir o conhecimento na sala de aula é sempre uma festa para o aluno. (SANTOS et al, 2009).

Contudo, é importante ressaltar que devido à alta demanda dos professores no contexto escolar, muitas vezes é difícil que esse profissional possa oferecer um atendimento mais específico que venha a suprir a necessidade do aluno com dificuldade de aprendizagem. Por isso, evidencia-se o trabalho multidisciplinar que precisa ser realizado, contando com outros atores e profissionais que possam garantir a esse aluno maiores condições de sucesso. A dificuldade de aprendizagem na leitura e escrita não deve ser considerada como um fracasso, mas sim como um desafio a ser enfrentado.

Okano et al (2004) destaca que lidar com as dificuldades de aprendizagem no ambiente escolar não é uma tarefa fácil. Uma alternativa é a colocação das crianças em programas especiais de ensino, como as salas de reforço ou de recuperação paralela, destinadas aquelas que apresentam dificuldades não superadas no cotidiano escolar.

\section{METODOLOGIA}

A pesquisa científica pode ser definida como um conjunto de procedimentos sistemáticos, fundamentados no raciocínio lógico e que utiliza métodos científicos para encontrar soluções para problemas propostos. (ANDRADE, 2001).

A abordagem adotada nesta pesquisa foi qualitativa, visto que ela permite abordar o problema em questão, destacando alguns pontos de vista e comportamentos de indivíduos ou 
grupos. Minayo (2003) define a pesquisa qualitativa como aquela que trabalha com o universo de significados, motivos, aspirações, crenças, valores e atitudes, o que corresponde a um espaço mais profundo das relações, dos processos e dos fenômenos que não podem ser reduzidos à operacionalização de variáveis.

Tal investigação aconteceu através de pesquisa bibliográfica, a partir de material já produzido sobre o tema, consultando livros, revistas e outros artigos científicos. Foi realizada uma pesquisa de campo com a pretensão de buscar informações a serem documentadas, sendo a coleta de dados realizada por meio de questionários online com os participantes da pesquisa. Estes questionários foram elaborados por meio da análise de conteúdo, com um direcionamento de perguntas com vistas a responder aos objetivos propostos com 4 (quatro) professoras, todas do $2^{\circ}$ ano do ensino fundamental I.

\section{APRESENTAÇÃO E ANÁLISE DOS RESULTADOS}

No decorrer da pesquisa constatou-se que é comum nessa fase de ensino que alguns alunos apresentem dificuldades de aprendizagem na leitura e na escrita, decorrentes, dentre outros fatores, da questão metodológica aplicada pelo professor em sala de aula. Ainda é comum no espaço escolar a adoção de métodos tradicionais de ensino, os quais não contribuem para uma efetiva aprendizagem.

Segundo Carraher e Schliemann (1989), quando uma criança não compreende o método de ensino adotado pelo professor ela se sente frustrada, com problemas de baixa autoestima, ficando desinteressada, desatenta e em certos casos até agressiva.

Logo, vê-se que é muito importante analisar a prática pedagógica para perceber a qualidade da atuação e o envolvimento com a aprendizagem dos educandos, pois é de suma importância entender que nesse processo cada pessoa aprende de forma diferente. Assim, a utilização de uma metodologia mais lúdica, dentro de uma perspectiva construtivista, oportuniza ao aluno mais autonomia no processo de desenvolvimento e aprendizagem.

De acordo com a pesquisa e as análises feitas, pode-se dizer que os alunos podem apresentar tal dificuldade em todas as matérias, uma vez que ler e escrever faz parte de todas as disciplinas. Por isso, é importante que o professor tenha consciência que o aluno apresenta tais dificuldades não por preguiça ou vontade própria e buscar trabalhar em cima dessas dificuldades, tentando recuperar a autoestima. Analisar os métodos de ensino é de fundamental importância para os educadores que enfrentam problemas relacionados à metodologia. 
No que diz respeito ao papel do professor diante dessas dificuldades e as técnicas utilizadas para melhorar o processo de ensino-aprendizagem desses alunos as participantes ressaltam que:

\section{E. M., 66 anos, Pedagoga}

O professor deve ter uma visão diagnóstica para o processo de aquisição da leitura e escrita dos alunos. Uma vez identificadas as dificuldades de cada um, deve-seincentivar a leitura e escrita dos alunos. O aluno que lê, escreve melhor. O papel do professor é diagnosticar as dificuldades dos alunos e planejar métodos para ajudar nessas dificuldades, buscando a família para também procurar ajuda nas dificuldades encontradas.

Devem ser observados o rendimento dos alunos em sala de aula, suas dificuldades em aprender, e o que levam muitos a perderem o interesse pela escola.

\section{E. R., 57 anos, Pedagoga}

O papel do professor deve ser observar, orientar e instruir o aluno na leitura para que o mesmo melhore diante desta circunstância.

Observar se a criança, ao ler o livro, aproxima-o muito do rosto, ou quando vai copiar algo do quadro. Na escrita, observar o tamanho das letras e como o aluno escreve, pois há alguns que escrevem misturando letras maiúsculas com minúsculas. Então, o professor deve orientá-los.

\section{M., 48 anos, Professora formada em Magistério}

Essa visão é simples nos livros didáticos, pois ainda existe termo de memorização das sílabas. O responsável pelo letramento deve dar prioridade e se responsabilizar com o aprendizado do aluno.

O aprendizado é para todos. O professor deve fazer uma diagnose para detectar os alunos com dificuldades de aprendizagem e que não assimilam bem as explicações do professor. Temos sempre que voltar às explicações ou fazer atividades diferenciadas, reconhecendo as peculiaridades e fazendo uma ação que possa ajudar no aprendizado de cada aluno.

Deve-se ainda observar a prática da psicomotricidade e afetividade na sala de aula e fazer uma diagnose comportamental dos alunos, buscando ajuda da família ou de um psicólogo, caso precise. É possivel que algum aluno apresente dificuldades de aprendizagem como a dislexia (leitura e escrita) e a dislalia (troca de letras). 


\section{S. M., 50 anos, Pedagoga com pós-graduação em Gestão Escolar}

O professor deve ter uma visão de facilitador, demonstrando a seus alunos como a leitura é algo maravilhoso. Deve ser um leitor, sempre lendo com entusiasmo. Isso levará à construção da leitura.

Há alunos que já estão no $5^{\circ}$ ano, mas têm muita dificuldade na leitura e, consequentemente, na interpretação. Isso é muito complicado, pois dificulta o entendimento das atividades de forma geral. Problemas na família também dificultam o desempenho dos alunos. As formas abreviadas de escrever também têm sido uma das dificuldades na atualidade, pois nas atividades querem escrever como fazem nas redes sociais.

O papel do professor é tentar descobrir o que está causando a dificuldade da criança na leitura e escrita e acionar a gestão e familiares na busca pela solução. Também deve mudar, se necessário, a metodologia de ensino. É preciso procurar conhecer as causas dessas dificuldades.

Emfim, deve-se observar o desempenho dos alunos em sala de aula; se eles têm dificuldades de ler e interpretar; se escrevem errado ou se não assimilam os conteúdos estudados.

Percebe-se, assim, a necessidade de se ter um novo olhar sobre tais questões, visando ser mais crítico e fundamentando as atividades para proporcionar ao aluno uma aprendizagem mais significativa. Para superar as dificuldades encontradas e promover o avanço cognitivo dos educandos, Piaget (1972) enfatiza que:

O papel do mestre deve ser aquele de incitar a pesquisa, de fazer tomar consciência dos problemas e não aquele de ditar a verdade. Não podemos nos esquecer que uma verdade imposta não é mais uma verdade: compreender é inventar e reinventar, e dar uma lição prematuramente é impedir a criança de redescobrir as soluções por si mesma. (PIAGET, 1972, p. 72).

Acredita-se na possibilidade de sanar as dificuldades de aprendizagem apresentadas pelos alunos, mas para isso é necessário que haja um trabalho voltado para uma ação reflexiva com toda a equipe pedagógica que abrange a direção, professores, pais, alunos e demais profissionais, procurando sempre trabalhar as questões didáticas com os professores, a relação família e escola, planejar estratégias que visem superar dificuldades encontradas, avaliar e assegurar o processo de ensino da aprendizagem de leitura e escrita, rever o currículo, inserir projetos pedagógicos, etc. Dessa maneira, a aprendizagem será satisfatória e significativa.

Assis (1990) menciona que os problemas de aprendizagem podem ser resultado de ambientes familiares que não estimulam as crianças a estudar e acredita que um ambiente familiar com pouca influência sociolinguística pode interferir no desenvolvimento das aptidões e habilidades desempenhadas pela criança. Muitos fatores podem intervir na vida 
escolar de uma criança. Um ambiente doméstico tranquilo e saudável proporcionará uma melhor estabilidade emocional.

Nesse sentido, Carraher e Schliemann (1989) asseveram que a responsabilidade em educar não é só da escola e nem recai apenas sobre a imagem do professor, uma vez que é de competência de todas as instituições sociais envolvidas. A família deve participar junto à escola, pois a ela compete a transmissão de valores morais.

Conforme exposto, não se pode esperar que o professor seja mero transmissor de informações ou que aprenda no ambiente acadêmico o que vai ser ensinado aos alunos, mas sim um docente que produza o conhecimento em sintonia com o aprendiz. Não é suficiente que ele saiba o conteúdo de sua disciplina, pois o mesmo precisa não só interagir com outras disciplinas, como também conhecer o aluno. Esse conhecimento/interação faz parte do papel desempenhado pelo professor pelo fato dele necessitar saber o que ensinar, para quê e para quem, ou seja, como o aluno vai utilizar o que aprendeu na escola em sua prática social.

Por fim, foi possível entender o importante papel do professor em proporcionar uma intervenção pedagógica multidisciplinar utilizando técnicas e estratégias lúdicas que possam prevenir, combater e evitar as dificuldades de aprendizagem na leitura e na escrita dentro do ambiente escolar.

\section{CONSIDERAÇÕES}

Com base na pesquisa bibliográfica e na pesquisa de campo, foi possível observar que as dificuldades de aprendizagem advêm de diversos fatores, podendo atingir grande parte dos alunos. Isso representa um desafio que precisa ser superado no âmbito escolar. Dessa forma, tal discussão não pode ser ignorada no contexto educativo, devendo-se ampliar o investimento no debate teórico e metodológico de tais questões, visando assim a sua superação.

Ficou nítida a percepção do quanto é importante ter no meio escolar o incentivo e a iniciativa de fazer com que os alunos passem a ter um novo olhar para a leitura, para que a escola alcance todas as metas estabelecidas no que se refere ao processo de ensinoaprendizagem. Dessa forma, a intervenção pedagógica deve ser no sentido de criar projetos, realizar oficinas pedagógicas com o intuito de prevenir e/ou até acabar com as dificuldades identificadas na instituição, ajudando os alunos a resolver situações problemas de forma mais significativa.

O incentivo à leitura também seria uma forma de estímulo para uma aprendizagem 
lúdica e atraente, contribuindo para amenizar ou até acabar com as dificuldades das crianças envolvidas. Destacam-se algumas queixas por parte dos professores em relação à presença de diversas dificuldades de aprendizagem, principalmente no que envolve a leitura, a interpretação e a compreensão das palavras, frases e textos. Foi possível perceber que os alunos, ao lerem ou escreverem, não conseguem interpretar de forma coerente fatos de sua própria realidade. Por isso, foi elaborada uma proposta de intervenção pedagógica visando oportunizar aos alunos a participação ativa em uma oficina de leitura e letramento, com jogos que envolvem leitura e escrita, objetivando acabar com a repetência dos mesmos ao priorizar a interação deles nas atividades propostas.

Portanto, a proposta colocada neste trabalho seria uma alternativa, dentre tantas outras já existentes, para amenizar a problemática. Ela deve ser aplicada na escola como um todo, uma vez que sua missão é garantir aos alunos que essa aprendizagem seja significativa para a vida deles.

\section{REFERÊNCIAS}

ANDRADE, M. M. Introdução à metodologia do trabalho cientifico. Elaboração de trabalhos na graduação. São Paulo: Atlas, 2001.

ASSIS, M. B. A. C. Aspectos afetivos do desempenho escolar: alguns processos inconscientes. Boletim da Associação Brasileira de Psicopedagogia, n. 20, p. 35- 48, 1990.

BARROS, A. J. S.; LEHFELD, N. A. S. Fundamentos de metodologia: um guia para a iniciação cientifica. 2. ed. São Paulo: Makron Books, 2000.

BOSSA, Nádia A. A psicopedagogia no Brasil: contribuições a partir da prática. Porto Alegre: Artmed, 2007.

CEEL/UFPE - Centro de Estudos em Educação e Linguagem da Universidade Federal de Pernambuco; MEC - Ministério da Educação. Jogos de Alfabetização. Pernambuco, 2009.

CEEL/UFPE - Centro de Estudos em Educação e Linguagem da Universidade Federal de Pernambuco; MEC - Ministério da Educação. Alfabetização e letramento: conceitos e relações. Pernambuco, 2007.

COELHO, M. T.; JOSÉ, E. A. Problemas de aprendizagem. 8. ed. São Paulo: Ática, 1996.

CARRAHER, T. N.; SCHLIEMANN, A. D. Fracasso escolar: uma questão social. Cadernos de pesquisa, n. 45, p.3-18, maio, 1983. 
. Na vida dez, na escola zero. São Paulo: Cortez Editora, 1989.

FONSECA, J. J. S. Metodologia da pesquisa científica. Fortaleza: UEC, 2002.

FREIRE, Paulo. Pedagogia da Esperança. São Paulo: Paz e Terra. 2000.

. Pedagogia da Autonomia: saberes necessários à pratica educativa. 29. ed. São Paulo: Paz e Terra, 2004.

GADOTTI. Moacir. Boniteza de um sonho: ensinar-e-aprender com sentido. Novo Hamburgo: Feevale, 2003.

GONÇAlveS, M. D. (2002). Concepções Científicas e Concepções Pessoais sobre o Conhecimento e Dificuldades de Aprendizagem. Disponível em: http://www.lispsi.pt/public/índex.htm. Acesso em: 14 jun. 2020.

LEITE, S. A. da S. O fracasso escolar no ensino de primeiro grau. Revista Brasileira de estudos Pedagógicos, v.69, n.163, p.510-540, setembro/dezembro, 1988.

KLEIMAN, Angela. Texto e Leitor: Aspectos Cognitivos da Leitura. 8. ed. Campinas: Pontes, 2002.

KIRK, S. A. Educating Exceptional Children. Boston: Houghton Mifflin, 1962.

MINAYO, M. C. S. et al. Pesquisa social. 22. ed. Petrópolis: Vozes, 2003.

NUNES, Terezinha. Dificuldades na aprendizagem da leitura: teoria e prática. 2. ed. São Paulo: Cortez, 2001.

OLIVEIRA, Vera Barros de. Jogos de regras e a resolução de problemas. 4. ed. Petrópolis, R. J: Vozes, 2010.

OKANO, Cynthia Barroso et al. Crianças com dificuldades escolares atendidas em programas de suporte psicopedagógico na escola: avaliação do auto conceito. Psicol. Reflex. Crit., 2004 vol.17, nº 1, p. 121-128.

PIAGET, J. Psicologia e Pedagogia. 2. ed. Rio de Janeiro: Forense, 1972.

PAIN, Sara. Diagnóstico e Tratamento dos Problemas de Aprendizagem. 4. ed. Porto Alegre: Artes Médicas, 1992.

SANTOS, Carla Cristina Pereira, et al. Dificuldades de Aprendizagem em Leitura e 
escrita nas series iniciais do ensino fundamental. Revista Cientifica em Educação a Distancia. 2009.

SIMÕES, Darcília M. P. Consideração sobre a fala e a escrita: Fonologia em nova chave. São Paulo: Parábola, 2006.

SOARES, M. B. Letramento - Um em três gêneros. Belo Horizonte: Ceale, Autêntica, 1998.

. Dimensões da não Aprendizagem. Curitiba, PR: IESEDE, 2012.

VEIGA, Ilma Passos Alencastro. Projeto Político Pedagógico da Escola: uma construção possível. Campinas: Papirus, 2009.

VYGOTSKY, Lev S. A formação social da mente. São Paulo: Martins Fontes, 1984.

\section{APÊNDICE A - Questionário de Perguntas (Professor)}

1-Qual a visão do professor sobre o processo de aquisição da leitura e da escrita?

2-Quais são as principais dificuldades de aprendizagem encontradas na leitura e na escrita?

3-Qual o papel do professor diante dessa dificuldade?

5-Quais os aspectos que devem ser observados no sujeito que apresenta dificuldade de aprendizagem?

\section{APÊNDICE B - Projeto desenvolvido na Escola Felipe Magalhães}

A Escola Felipe Magalhães, na qual foi realizada a pesquisa, pertence à área urbana do município de Jaboatão dos Guararapes, localizada no bairro de Candeias, zona sul de Pernambuco. Atualmente a escola tem 350 alunos matriculados com 08 turmas funcionando pela manhã e 08 turmas à tarde, com faixa etária dos alunos de 02 a 10 anos, atendendo a várias comunidades da redondeza.

A estrutura física atual é distribuída por dois prédios. Um prédio principal térreo, onde fica a administração da escola e o ensino da educação infantil e outro prédio onde fica o ensino fundamental I que foi inaugurado em 2018. A escola é composta por uma equipe de uma diretora, um vice-diretor, uma coordenadora, duas auxiliares, onze professores 
contratados, um cantineiro e dois auxiliares de serviços gerais.

A equipe gestora é formada por professores graduados em letras, educação física, pedagogia e pós-graduados, com especialização em educação especial, e a equipe de infraestrutura é formada por profissionais desde o nível fundamental incompleto até graduados. Possui um conselho de classe com participação ativa, em que são realizadas reuniões em busca de melhorias que minimizem as dificuldades, visand o o bem-estar de todos os envolvidos no processo de ensino e aprendizagem. A escola baseia sua prática educativa com vistas a buscar a superação dos obstáculos, desenvolvendo ações, projetos didáticos e de intervenção ao longo do ano letivo.

A partir da análise dos dados, percebeu-se que apesar da aceitação e qualificação da escola, existe certa insatisfação com o rendimento da turma do $2^{\circ}$ ano do ensino fundamental I, com relação à leitura e ao letramento. Assim, como proposta e indicação para tentar ajudar os alunos frente a essa problemática, fica como sugestão o incentivo e estímulo da família em ajudar a manter um momento de leitura em casa, para assim ampliar o repertório de vivências. $\mathrm{Na}$ escola, com a mediação do professor, deve-se investir nas dinâmicas e metodologias diferenciadas, como uma oficina de jogos de leitura e a construção de um caderno de texto, conforme explicado no modelo abaixo.

Lista de jogos de leitura e letramento para serem confeccionados e trabalhados na oficina realizada pelos alunos:

- $\quad$ Cubos com sílabas;

- Jogo da coesão e coerência;

- Jogo da roleta;

- $\quad$ Bingo silábico;

- Pião silábico;

- Tabela de leitura.

Os alunos confeccionarão os jogos e criarão as regras de cada jogo. Os jogos serão trabalhados com os alunos e, por último, apresentado em uma feira de conhecimento.

Regras para a produção do Caderno de Texto:

1- Antes de usar este caderno leia com atenção. Ele é de uso coletivo. Então, cuide muito bem dele e traga-o na data combinada para que outro colega possa levá-lo;

2- Cuidados que deveremos ter com as produções de textos:

- $\quad$ A letra bem feita para que qualquer pessoa possa ler;

- $\quad$ Procure ler e reler sempre o que escreveu; 
- Use letras maiúsculas ao iniciar frases e ao escrever nomes próprios;

- $\quad$ Faça parágrafo sempre que iniciar uma nova frase;

- Tenha organização e capricho;

- Use a criatividade nas suas histórias;

- Tendo dúvidas peça ajuda a um adulto;

- $\quad$ Leia as histórias dos seus amigos;

- $\quad$ Não risque as histórias deles;

- $\quad$ Não apague as histórias que foram feitas;

- $\quad$ Cuide com carinho do CADERNO;

- $\quad$ Agora é só soltar a imaginação e escrever! 